\title{
Impact of Cox maze procedure on outcome in patients with atrial fibrillation and mitral valve disease
}

\author{
Ko Bando, $\mathrm{MD}^{\mathrm{a}}$ \\ Junjiro Kobayashi, MD ${ }^{a}$ \\ Yoshio Kosakai, MD \\ Mitsuhiro Hirata, MD \\ Yoshikado Sasako, MD \\ Satoshi Nakatani, MDC \\ Toshikatsu Yagihara, MD ${ }^{a}$ \\ Soichiro Kitamura, $\mathrm{MD}^{\mathrm{a}}$
}

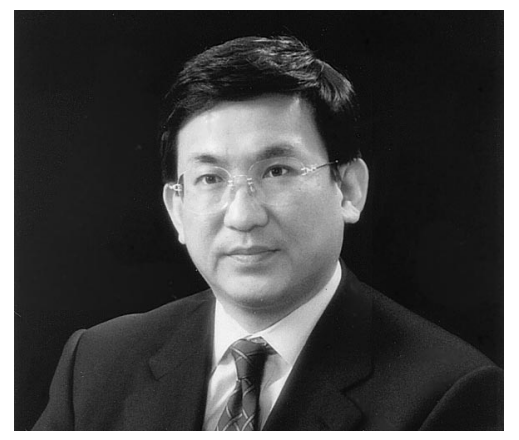

Dr Bando

From the Departments of Cardiovascular Surgery and Cardiology, ${ }^{\mathrm{c}}$ National Cardiovascular Center, Osaka, and Takarazuka Municipal Hospital, ${ }^{\mathrm{b}}$ Takarazuka, Japan.

Read at the Eighty-first Annual Meeting of The American Association for Thoracic Surgery, San Diego, Calif, May 6-9, 2001.

Received for publication May 15, 2001; revisions requested July 27, 2001; revisions received Dec 20, 2001; accepted for publication Dec 27, 2001.

Address for reprints: Ko Bando, MD, Department of Cardiovascular Surgery, National Cardiovascular Center, 5-7-1, Fujishirodai, Suita, Osaka, 565-8565, Japan (E-mail: kobando@hosp.ncvc.go.jp).

J Thorac Cardiovasc Surg 2002;124:575-83

Copyright $(9) 2002$ by The American Association for Thoracic Surgery

0022-5223/2002 \$35.00+0 $\quad \mathbf{1 2 / 6 / 1 2 4 3 9 2}$

doi:10.1067/mtc.2002.124392
Objective: We sought to determine whether the Cox maze procedure provides additional benefit to patients with atrial fibrillation undergoing mitral valve operations.

Methods: Between May 1992 and August 2000, we performed 258 Cox maze procedures with mitral valve replacement $(n=147)$ or mitral valve repair $(n=$ 111). We compared the outcomes of these patients with those of 61 control patients with preoperative atrial fibrillation who underwent mitral valve replacement alone during the same interval. The three cohorts were similar in age, sex, and proportion of patients in preoperative New York Heart Association functional class 3 or 4.

Results: Although 5-year survivals were similar among the groups (94\% for mitral valve replacement alone, $95 \%$ for mitral valve replacement plus maze, and $97 \%$ for mitral valve repair plus maze), freedoms from atrial fibrillation at 5 years were significantly higher in the mitral valve replacement plus maze group (78\%) and the mitral valve repair plus maze group $(81 \%)$ than in the mitral valve replacement group $(6 \%, P<.0001)$. Freedoms from stroke at 5 years were $97 \%$ for the mitral valve replacement plus maze group, $97 \%$ for the mitral valve repair plus maze group, and only $79 \%$ for mitral valve replacement group $(P<.0001)$. Multivariable analysis with Cox hazard model revealed that the most significant risk factor for late stroke was the omission of the Cox maze procedure $(P=.003)$.

Conclusions: The addition of the Cox maze procedure to mitral valve repair and replacement was safe and effective for selected patients. Elimination of atrial fibrillation significantly decreased the incidence of late stroke.

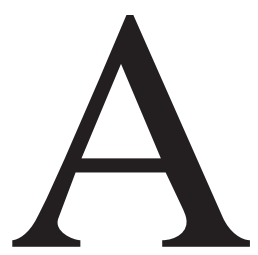

pproximately $40 \%$ to $60 \%$ of patients who undergo mitral valve surgery have chronic atrial fibrillation before the operation, ${ }^{1-3}$ and most remain in atrial fibrillation after the operation. ${ }^{4}$ Although several authors have reported that atrial fibrillation can be successfully ablated with the Cox maze procedure in patients undergoing mitral valve procedures,, 56 few studies have demonstrated a long-term benefit in terms of reduced late morbidity and mortality associated with the elimination of atrial fibrillation. ${ }^{7}$ Several studies have reported the benefit of a Cox maze procedure combined with mitral valve repair. However, most surgeons do not perform a maze procedure in patients who require mitral valve replacement, especially with mechanical valves, because most of these patients will be maintained on systemic anticoagulation, which is presumed to result in a low risk of postoperative thromboembolism. Although anticoagulation is beneficial, however, it does 
TABLE 1. Preoperative clinical characteristics

\begin{tabular}{|c|c|c|c|c|}
\hline Variable & MVR & MVR/maze & MVP/maze & $P$ value \\
\hline Sex (male/female ratio) & 28:33 & 55:92 & 70:41 & - \\
\hline Age $(y$, mean $\pm S D)$ & $62.9 \pm 8.6$ & $58.8 \pm 8.3$ & $59.4 \pm 11.0$ & - \\
\hline $\begin{array}{l}\text { New York Heart Association class III or } \\
\text { IV (No.) }\end{array}$ & $33(54.1 \%)$ & $69(46.9 \%)$ & $41(36.9 \%)$ & .051 \\
\hline History of stroke (No.) & $11(19.6 \%)$ & $36(24.5 \%)$ & $7(6.3 \%)$ & .001 \\
\hline Left atrial thrombus (No.) & $2(3.6 \%)$ & $11(7.5 \%)$ & $6(5.4 \%)$ & .56 \\
\hline Previous heart surgery (No.) & $28(45.9 \%)$ & $24(16.3 \%)$ & $6(5.4 \%)$ & $<.0001$ \\
\hline Chronic atrial fibrillation (No.) & $61(100 \%)$ & $143(97.3 \%)$ & $105(94.6 \%)$ & .16 \\
\hline Preoperative f wave $<0.1 \mathrm{mV}$ (No.) & $49(80.3 \%)$ & $14(9.5 \%)$ & $5(4.5 \%)$ & $<.0001$ \\
\hline Duration of atrial fibrillation $>20$ y (No.) & $28(45.9 \%)$ & $23(15.6 \%)$ & $11(9.9 \%)$ & $<.0001$ \\
\hline
\end{tabular}

not abolish the risk of stroke associated with atrial fibrillation. ${ }^{7}$ We have used the Cox maze procedure in conjunction with both mitral valve repair and replacement (even with mechanical valves) in patients with significant mitral disease and atrial fibrillation in the expectation of a lower risk of thromboembolism and improved cardiac function when sinus rhythm is maintained. The purpose of this study was to assess the early- and late-term results of a Cox maze procedure combined with mitral valve repair or replacement.

\section{Patients and Methods}

Between May 1992 and September 2000, we performed 258 Cox maze procedures combined with mitral valve replacement (MVR/ maze, $n=147$ ) or repair (MVP/maze, $n=111)$ at the National Cardiovascular Center, Osaka, Japan. We compared the outcomes of these patients with those of 61 patients with preoperative atrial fibrillation who underwent MVR alone during the same interval.

We retrospectively reviewed the data from operative notes, anesthesia records, clinical case histories, and laboratory investigations, including electrocardiograms, echocardiograms, and cardiac catheterization reports. Follow-up data were collected from National Cardiovascular Center records of outpatient visits and correspondence with referring physicians. A total of 319 clinical hemodynamic, electrocardiographic, and echocardiographic variables were entered into a computerized database and analyzed. Follow-up data for more than 6 months after the operations were available for all patients. Morbid events were analyzed for both the early (in hospital) and late (after discharge) periods. Stroke was defined as cerebral thromboembolism and was clearly differentiated from transient ischemic attack.

\section{Patients}

Demographic data and preoperative cardiac information are given in Table 1. Although the proportions of patients with left atrial thrombus were similar in all groups, the MVR/maze group had a higher incidence of previous stroke. Patients who underwent MVR alone had a higher incidence of previous heart surgery (Table 1). With respect to preoperative heart rhythm, most patients in each group had chronic atrial fibrillation. A maze procedure combined with mitral valve repair (MVP/maze; $n=4)$ or replacement $(\mathrm{MVR} / \mathrm{maze} ; \mathrm{n}=3)$ was performed for 7 patients who had multiple episodes of paroxysmal atrial fibrillation necessitating long-term anticoagulation. The duration of preoperative atrial fibrillation was significantly longer among patients with MVR alone than among patients who underwent MVP/maze or MVR/maze (Table 1). Patients undergoing MVR without a maze procedure had the maze procedure omitted primarily because of multiple previous heart operations, duration of preoperative atrial fibrillation longer than 20 years, $\mathrm{f}$-wave in $\mathrm{V}_{1}$ leads less than $0.1 \mathrm{mV}$, left atrial dimension larger than $70 \mathrm{~mm}$, and emergency surgery.

\section{Surgical Procedure}

Most patients in the MVR group ( $\mathrm{n}=57 / 61)$ and the MVR/maze group $(\mathrm{n}=143 / 147)$ received mechanical valves. Methods of mitral valve repair in the $\mathrm{MVP} /$ plus maze group varied according to the pathologic findings. The Cox maze II/III, Kosakai maze, and further modification of Kosakai maze (cryomaze) procedures were used (Figure 1). ${ }^{7-9}$ In the Kosakai maze procedure, cryoablation was used to avoid cutting the sinus node artery, which may result in sick sinus syndrome. A modification of the Kosakai maze procedure included use of cryoablation around the edge of the left pulmonary veins, avoiding the incision encircling all four orifices of the pulmonary veins.

\section{Statistical Methods}

Comparisons of the characteristics in the three groups were performed with a $\chi^{2}$ test for nominal variables and a nonparametric analysis of variance followed by a post hoc Bonferroni test for continuous and ordinal variables. Survivals and freedoms from atrial fibrillation and stroke were estimated by the Kaplan-Meier method. Survival curves were compared with a log-rank test. The risks for recurrence of atrial fibrillation and stroke were analyzed by both univariate analysis and multivariate analysis with the Cox proportional hazards model.

\section{Results}

Pathophysiologic Characteristics of Mitral Valve Disease and Operative Findings

The pathophysiologic characteristics of the mitral valve disease and the concomitant procedures are depicted in Table 2. There were no significant differences between the groups in terms of the incidence of associated procedures. All patients underwent surgery with mild hypothermia and 

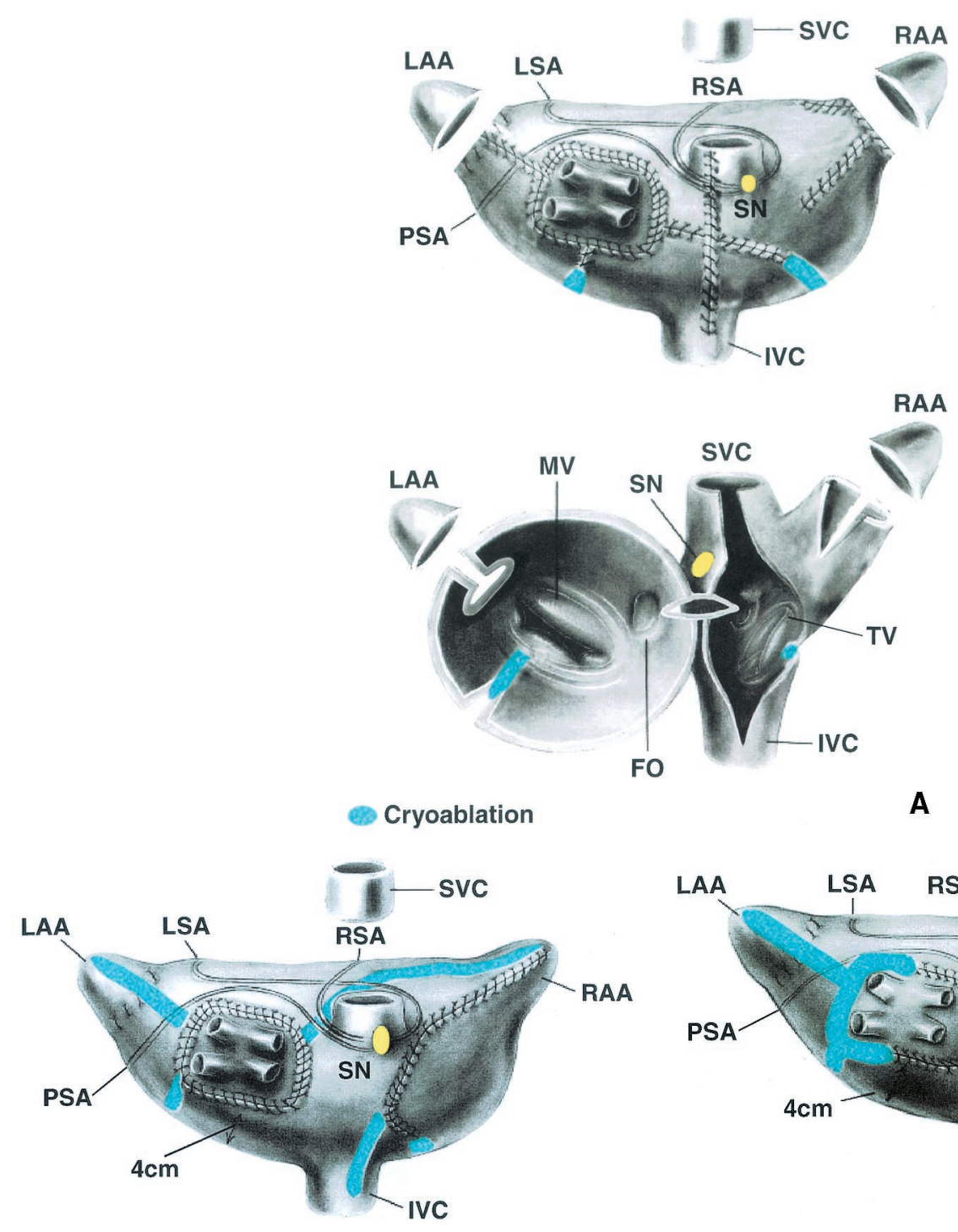

A
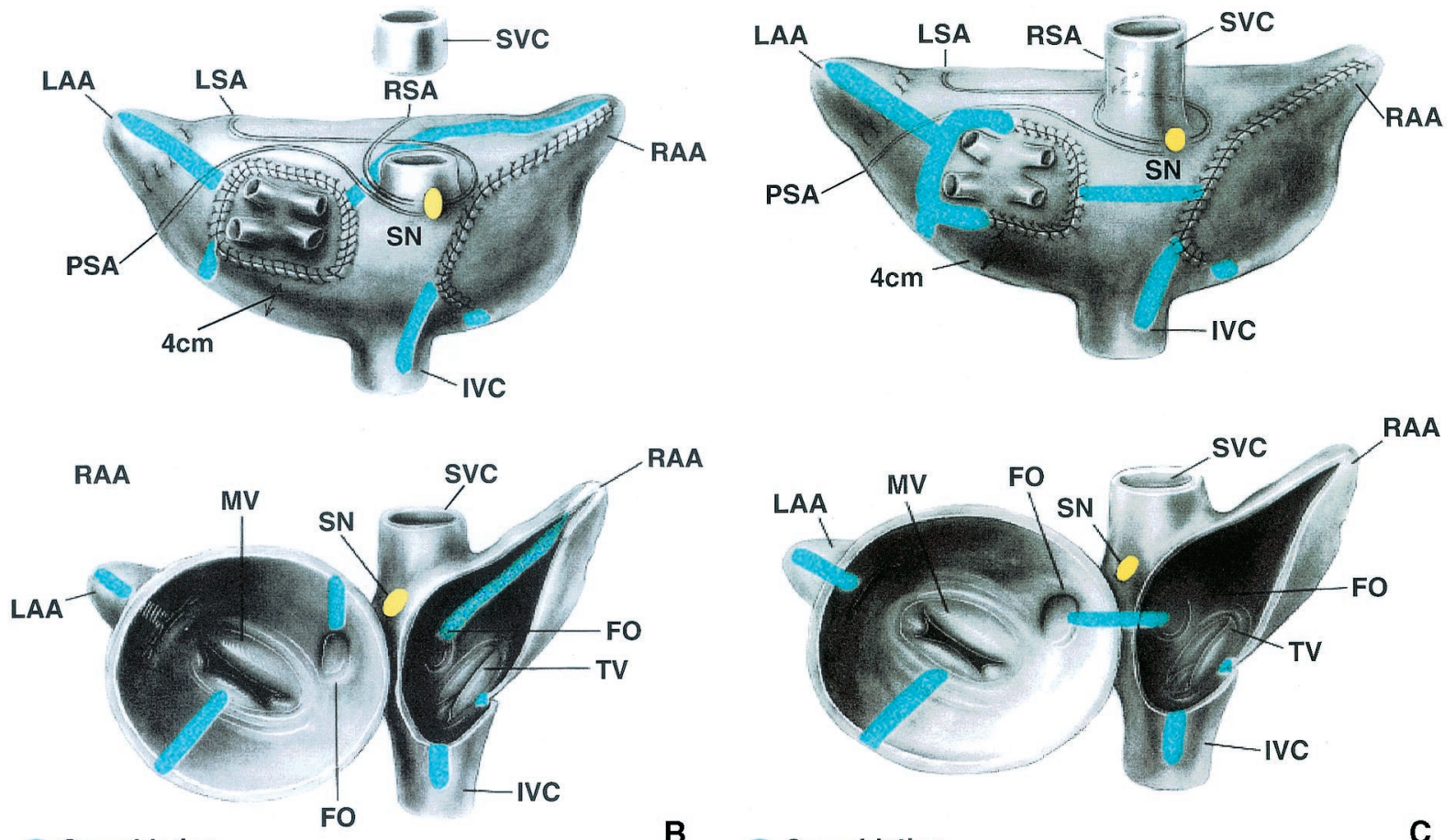
RAA

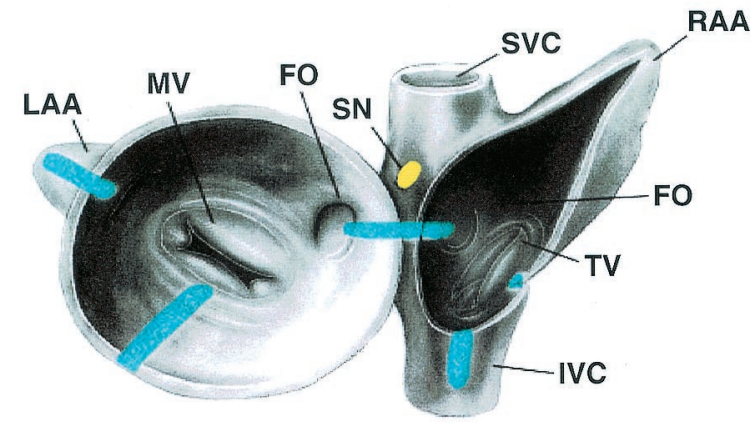

B

Cryoablation

Figure 1. Techniques of maze procedure performed in this study. A, Cox maze III procedure; B, Kosakai maze procedure; C, Cryomaze procedure. SVC, Superior vena cava; $R A A$, right atrial appendage; $L A A$, left atrial appendage; $L S A$, left sinus node artery; $R S A$, right sinus node artery; $S N$, sinus node, $P S A$, posterior sinus node artery; IVC, inferior vena cava; $M V$, mitral valve; $T V$, tricuspid valve; FO, foramen ovale. 
TABLE 2. Pathophysiologic characteristics of mitral disease and concomitant procedures

\begin{tabular}{|c|c|c|c|}
\hline & $\begin{array}{c}\text { MVR } \\
(n=61)\end{array}$ & $\begin{array}{l}\text { MVR/maze } \\
(\mathrm{n}=147)\end{array}$ & $\begin{array}{c}\text { MVP/maze } \\
(n=111)\end{array}$ \\
\hline \multicolumn{4}{|l|}{ Pathophysiologic characteristics (No.) } \\
\hline Mitral stenosis & 22 & 69 & \\
\hline Mitral regurgitation & 15 & 33 & 93 \\
\hline Mitral stenosis and regurgitation & 5 & 31 & 5 \\
\hline Prosthetic valve failure & 19 & 14 & 0 \\
\hline \multicolumn{4}{|l|}{ Concomitant procedures (No.) } \\
\hline Tricuspid annuloplasty & $37(60.7 \%)$ & $59(40.5 \%)$ & $45(40.5 \%)$ \\
\hline Coronary artery bypass grafting & $1(1.6 \%)$ & $5(3.4 \%)$ & $3(2.7 \%)$ \\
\hline Atrial septal defect closure & 0 & $2(1.4 \%)$ & $7(6.3 \%)$ \\
\hline
\end{tabular}

combined antegrade and retrograde blood cardioplegia. The aortic crossclamp times and cardiopulmonary bypass times were not significantly different among the groups. The proportions of patients who underwent concomitant ligation of the left atrial appendage were similar among the groups (MVR, $\mathrm{n}=45 / 61,74 \%$, MVR/maze, $\mathrm{n}=102 / 147,69 \%$, and MVP/maze, $\mathrm{n}=77 / 111,70 \%, P=.79$ ).

\section{Postoperative Morbidity and Mortality}

In-hospital deaths included 1 patient who underwent MVR (low output syndrome), 2 patients in the MVR/maze group (multiple organ failure), and 2 patients in the MVP/maze group (mediastinitis in 1 case and multiple organ failure in 1 case). Postoperative complications included bleeding $(\mathrm{n}=$ $7)$, intraoperative balloon pump insertion $(\mathrm{n}=2)$, mediastinitis $(\mathrm{n}=2)$, left ventricular assist device insertion $(\mathrm{n}=$ $1)$, pneumothorax $(n=1)$, and renal failure $(n=1)$. There were no differences among the three cohorts in the incidence of complications.

\section{Survival and Late Outcomes}

All patients were observed for at least 6 months after the operation. Although the actuarial 5-year survival of the patients with MVR alone (94\%) was lower than those of the MVR/maze (95\%) and MVP/maze (97\%) groups, this difference did not reach statistical significance $(P=.18$; Figure 2). There were 10 late deaths. In the MVR alone group, 2 patients died of unknown causes, 1 had intracerebral bleeding, 1 had cerebral infarction, and 1 died of an arrhythmia. In the MVR/maze group, 4 late deaths were due to intracerebral bleeding $(\mathrm{n}=1)$, arrhythmia $(\mathrm{n}=1)$, left ventricular rupture $(\mathrm{n}=1)$, and pneumonia $(\mathrm{n}=1)$. In the $\mathrm{MVP} /$ maze group, 1 late death was caused by liver cancer.

We chose to analyze the recurrence of arrhythmia after the first 30 days because early postoperative atrial fibrillation may be caused by a mechanism that differs from that of chronic atrial fibrillation. Freedom from atrial fibrillation after 3 years was $6 \%$ in the MVR group, compared with $84 \%$ and $85 \%$ in the MVR/maze and MVP/maze groups $(P<.001$; Figure 3).
Freedom from stroke after 5 years was $79 \%$ in the MVR group, compared with $97 \%$ in the MVR/maze and MVP/ maze groups $(P=.0001$; Figure 4$)$.

\section{Electrocardiography}

At the time of their discharge from the hospital, $81 \%$ to $83 \%$ of patients in the combined MVP/maze and MVR/maze groups were free of atrial fibrillation, compared with $5 \%$ in the MVR group $(P<.001$; Table 3$)$. Seventeen patients required pacemaker implantation after the operation: 8 in the MVR/maze group, 8 in the MVP/maze group, and 1 in the MVR group. At the most recent follow-up, $72 \%$ to $76 \%$ of patients in the MVR/maze and MVP/maze groups still remained free of atrial fibrillation, compared with only $7 \%$ of those in the control group (Table 3). A total of 16 patients required permanent pacemaker implantation for profound bradycardia with underlying atrial fibrillation after a combined maze procedure and MVP or MVR (Table 3).

\section{Late Functional Outcome}

Preoperative New York Heart Association functional class breakdowns were similar among the groups, whereas the proportion of the patients in postoperative New York Heart Association functional class II or higher was significantly greater among the patients with MVR alone $(n=20 / 56$, $35.8 \%$ ) than in the other two groups (MVR/maze, $\mathrm{n}=$ 14/145, 9.7\%, MVP/maze, $\mathrm{n}=9 / 109,8.3 \%, P<.001)$.

\section{Preoperative and Postoperative Medications}

The spectra and intensities of preoperative antiarrhythmic drugs were comparable among the three cohorts, but after the operation the number of antiarrhythmic agents decreased with time in the combined MVR/maze and MVP/ maze groups. At most recent follow-up, $35 \%$ of the patients in the MVR/maze group and $48 \%$ of the patients in the MVP/maze group needed no antiarrhythmic agents, whereas only $13 \%$ of those in the MVR group did not need these medications $(P<.0001)$. The vast majority of patients in the MVR group continued to receive $\beta$-blockers and digoxin for heart rate control. 


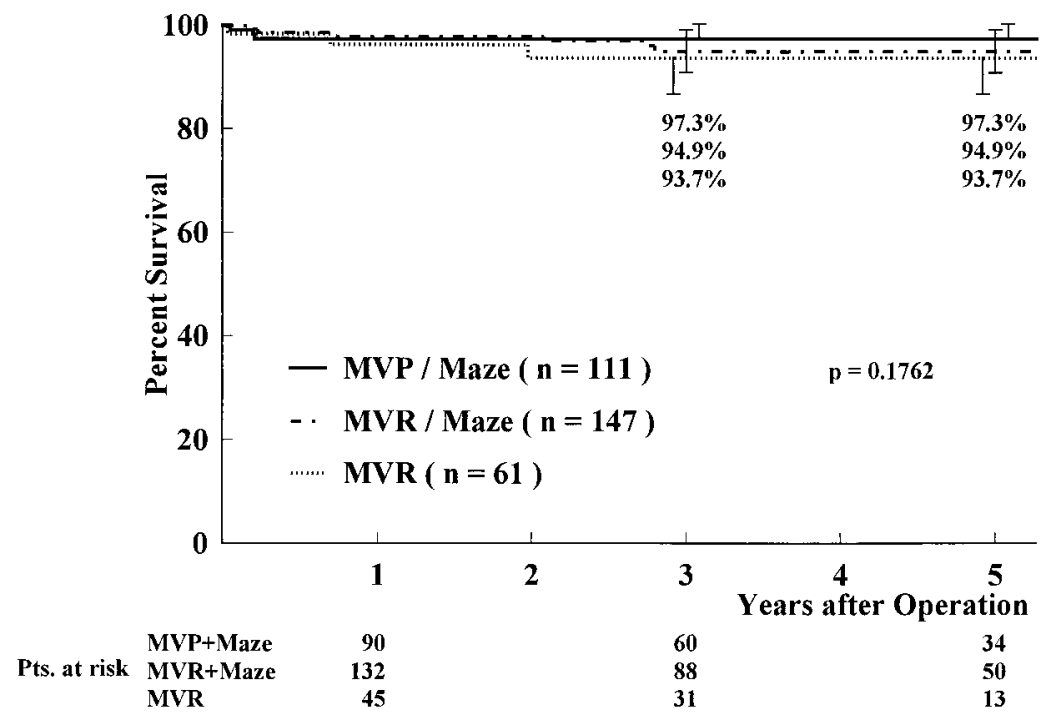

Figure 2. Actuarial survival curves for MVP/maze (solid line, $\mathbf{n}=111$ ), MVR/maze (long and short dashed line, $\mathrm{n}=$ 147), and MVR (dotted line, $n=61$ ) groups. Error bars indicate $95 \%$ confidence interval. $P=.1762$ by log-rank test.

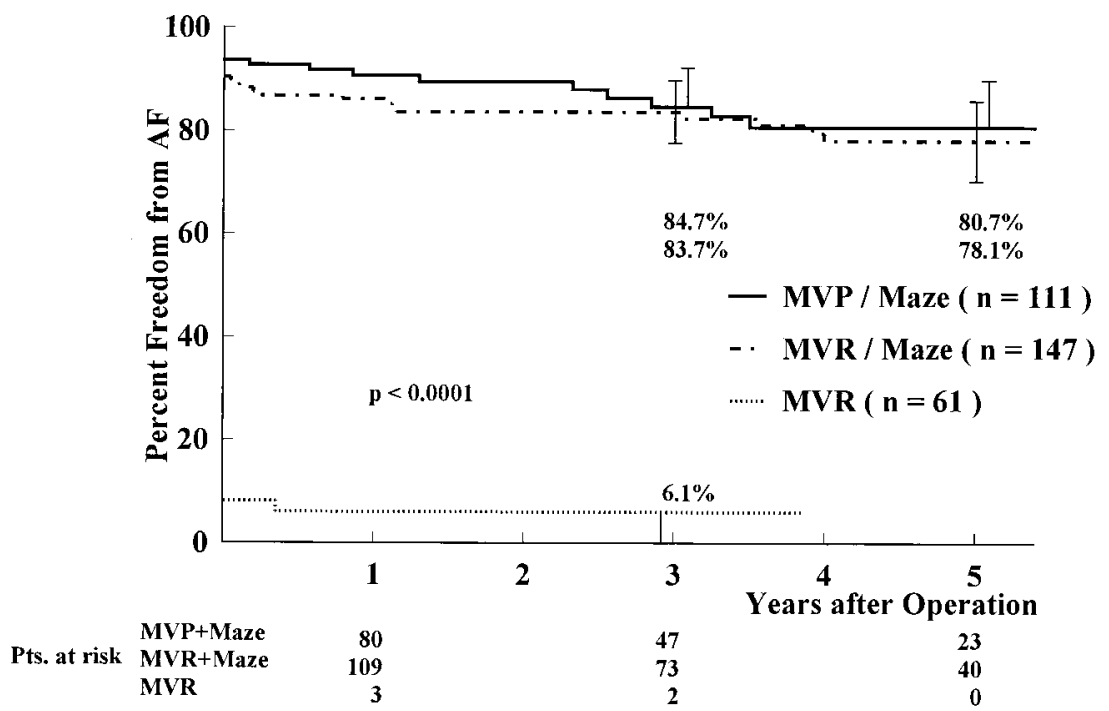

Figure 3. Freedom from recurrence of atrial fibrillation (AF) curves for MVP/maze (solid line, $n=111$ ), MVR/maze (long and short dashed line, $\mathrm{n}=147$ ), and MVR (dotted line, $\mathrm{n}=61$ ) groups. Error bars indicate $95 \%$ confidence interval. $P<.0001$ by log-rank test.

With respect to warfarin, $100 \%$ of the patients in the MVR group and $97 \%$ of the patients in the MVR/maze group were receiving warfarin at most recent follow-up, whereas only $35 \%$ of the patients in the $\mathrm{MVP} /$ maze group required warfarin $(P<.0001)$. In the MVP/maze group, warfarin administration was continued for patients who had at least one episode of postoperative atrial fibrillation.
Risk Factors for Recurrence of Atrial Fibrillation Risk factors for recurrence of atrial fibrillation were analyzed by univariate and multivariable analyses. According to univariate analysis, omission of the maze procedure and duration of chronic atrial fibrillation for longer than 20 years were significant risk factors for recurrence of atrial fibrillation. According to multivariable analysis, the omission of a maze procedure and longer duration of chronic atrial fibril- 


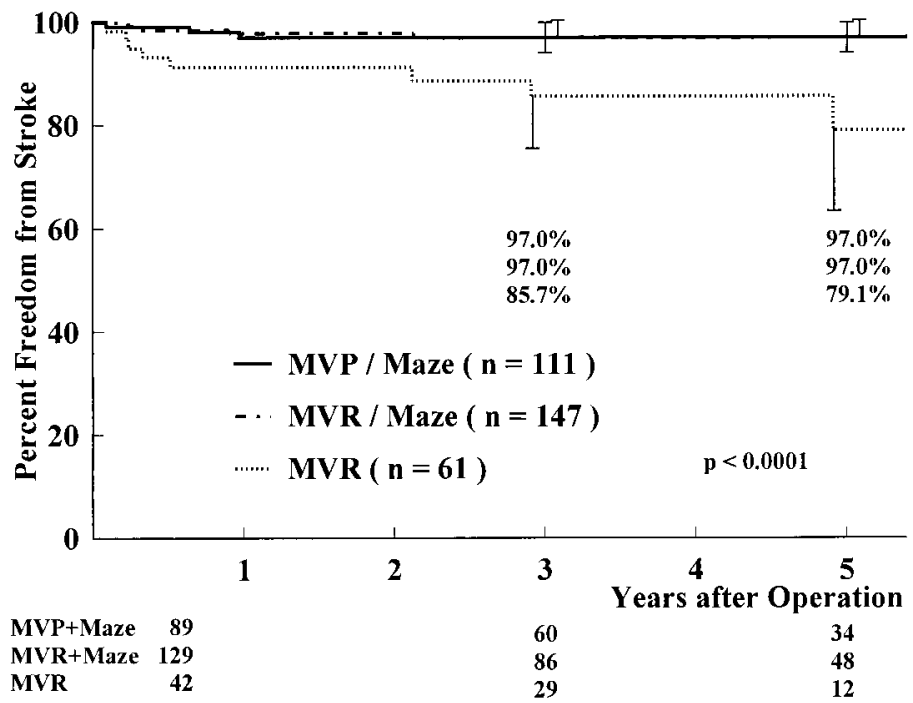

Figure 4. Freedom from late stroke curves for MVP/maze (solid line, $\mathrm{n}=111$ ), MVR/maze (long and short dashed line, $\mathrm{n}=147$ ), and MVR (dotted line, $\mathrm{n}=61$ ) groups. Error bars indicate $95 \%$ confidence interval. $P<.0001$ by log-rank test.

TABLE 3. Comparison of heart rhythms in each group

\begin{tabular}{|c|c|c|c|c|c|c|}
\hline & \multicolumn{2}{|c|}{ MVR } & \multicolumn{2}{|c|}{ MVR/maze } & \multicolumn{2}{|c|}{ MVP/maze } \\
\hline & No. & $\%$ & No. & $\%$ & No. & $\%$ \\
\hline \multicolumn{7}{|l|}{ Rhythm at discharge } \\
\hline Normal sinus rhythm & 3 & 5.0 & 118 & 81.4 & 90 & 82.6 \\
\hline Atrial fibrillation & 57 & 95.0 & 22 & 15.2 & 10 & 9.2 \\
\hline Atrial flutter & 0 & 0 & 2 & 1.4 & 4 & 3.7 \\
\hline Junctional & 0 & 0 & 2 & 1.4 & 4 & 3.7 \\
\hline Pacing & 0 & 0 & 0 & & 1 & 0.9 \\
\hline \multicolumn{7}{|c|}{ Most recent follow-up rhythm } \\
\hline Normal sinus rhythm & 3 & 5.0 & 105 & 72.4 & 83 & 76.1 \\
\hline Atrial fibrillation & 56 & 93.3 & 30 & 20.7 & 16 & 14.7 \\
\hline Atrial flutter & 0 & 0 & 0 & 0 & 0 & 0 \\
\hline Junctional & 0 & 0 & 2 & 1.4 & 2 & 1.8 \\
\hline Pacing & 1 & 1.7 & 8 & 5.5 & 8 & 7.3 \\
\hline
\end{tabular}

lation were risk factors for recurrent atrial fibrillation (Table 4).

\section{Incidence of Stroke After Surgery}

During the hospital stay, 2 patients in the MVR group had strokes (operation related in 1 case and inadequate anticoagulation in 1 case) and 1 patient in the MVP/maze group had a stroke (operation related). After discharge, 12 patients had strokes related to recurrent atrial fibrillation. There were 10 strokes among patients who were receiving adequate anticoagulation (6 in the MVR group, 2 in the MVR/maze group, and 2 in the MVP/maze group). Another 2 patients had strokes during periods of inadequate anticoagulation.

\section{Risk Factors for Late Stroke}

According to univariate analysis, the omission of a maze procedure and recurrence of atrial fibrillation 1 month after surgery or at the time of discharge were risk factors for late stroke (Table 5). According to multivariate analysis, the omission of a maze procedure was the most significant risk factor for late stroke (Table 5). Except for 2 of the patients in the MVR group, all patients had adequate anticoagulation with warfarin at the time of any strokes.

\section{Discussion}

Atrial fibrillation, one of the most common forms of cardiac arrhythmia, may cause significant morbid events, including systemic embolism, hemodynamic compromise, palpita- 
TABLE 4. Results of univariate and multivariate analyses of risk factors for recurrence of atrial fibrillation

\begin{tabular}{|c|c|c|c|c|}
\hline \multirow[b]{2}{*}{ Variable } & \multirow[b]{2}{*}{$\begin{array}{l}\text { Univariate analysis } \\
\qquad \boldsymbol{P} \text { value }\end{array}$} & \multicolumn{3}{|c|}{ Multivariate analysis } \\
\hline & & $\begin{array}{c}P \\
\text { value }\end{array}$ & Hazard ratio & $\begin{array}{c}95 \% \text { Confidence } \\
\text { interval }\end{array}$ \\
\hline No Cox maze procedure & $<.0001$ & .028 & 2.26 & $1.09-4.67$ \\
\hline Preoperative left atrial dimension $>70 \mathrm{~mm}$ & .0029 & .39 & 1.46 & $0.62-3.16$ \\
\hline Duration of chronic atrial fibrillation $>20 y$ & $<.001$ & .0001 & 3.67 & $1.89-7.11$ \\
\hline
\end{tabular}

TABLE 5. Results of univariate and multivariate analyses of risk factors for late stroke

\begin{tabular}{lcccc}
\hline & & \multicolumn{2}{c}{ Multivariate analysis } \\
\cline { 3 - 5 } Variable & $\begin{array}{c}\text { Univariate analysis } \\
\boldsymbol{P} \text { value }\end{array}$ & $\begin{array}{c}\boldsymbol{P} \\
\text { value }\end{array}$ & Hazard ratio & $\begin{array}{c}\text { Confidence } \\
\text { interval }\end{array}$ \\
\hline No Cox maze procedure & $<.0001$ & .0038 & 9.9 & $2.10-46.8$ \\
Preoperative left atrial dimension $>70 \mathrm{~mm}$ & .059 & - & -73 & 1.24 \\
Duration of chronic atrial fibrillation $>20 \mathrm{y}$ & .13 & .39 & 2.16 & $0.38-4.02$ \\
Recurrent atrial fibrillation at discharge & .0013 & $0.38-12.45$ \\
\hline
\end{tabular}

tions, and adverse reactions to antiarrhythmic agents and anticoagulants. The Cox maze procedure was designed to prevent chronic and paroxysmal atrial fibrillation and flutter, and several studies have confirmed the effectiveness of this procedure. Encouraged by this early success, the indications have been extended from isolated atrial fibrillation to the treatment of chronic atrial fibrillation in patients undergoing other cardiac operations, including those for mitral valve disease, atrial septal defects, coronary artery disease, and Fontan circulation. ${ }^{10,11}$ However, few studies have demonstrated a long-term benefit of this procedure in reducing late morbidity and improving functional outcomes.

In our study more than $97 \%$ of patients who underwent a combined maze procedure and mitral valve operation survived the operations, and $95 \%$ to $97 \%$ of those patients are still alive 5 years later (Figure 2). Furthermore, the addition of maze procedures to the mitral valve operations did not increase the number of morbid events in the immediate postoperative period. These results confirm the safety of a maze procedure as an adjunct to MVP or MVR.

Maintenance of normal sinus rhythm after a maze procedure improves atrial function. ${ }^{12}$ However, the most important potential benefit of the maze procedure is prevention of late stroke. ${ }^{7}$ Our results indicated that a maze procedure combined with a mitral valve operation restored regular rhythm in $84 \%$ to $85 \%$ of patients at 3 years after surgery (Figure 3 ), whereas only $6 \%$ of patients with MVR alone avoided recurrent atrial fibrillation at 3 years after surgery. Accordingly, $97 \%$ of these patients were free from late stroke at 5 years after surgery, compared with only $79 \%$ of patients who underwent MVR alone.

Some surgeons do not perform maze procedure in addition to MVR with mechanical valves because these patients receive systemic anticoagulation after surgery. In our study, however, 8 of the 10 late strokes among patients receiving optimal anticoagulation with warfarin occurred after MVR with mechanical valves. These results indicate that although anticoagulation is beneficial, it does not abolish the risk of stroke associated with atrial fibrillation. ${ }^{13-15}$ Furthermore, these results indicate that the current anticoagulant strategy of warfarin alone may not be adequate to prevent late strokes among these patients. ${ }^{16}$

Risk factor analysis for late stroke revealed that the omission of a maze procedure and recurrent atrial fibrillation at discharge were significant risks according to univariate analysis (Table 5). According to multivariate analysis, the omission of a maze procedure was the most significant risk for the development of late stroke (Table 5). Moreover, in the MVR/maze and MVP/maze groups, late strokes occurred in 4 patients in whom atrial fibrillation recurred after an unsuccessful maze procedure. These findings confirm that the restoration of sinus rhythm after mitral valve surgery by a maze procedure is the most effective means of preventing late strokes.

The major limitation of our study is that it was not randomized, and there were significant differences between the baseline characteristics of patients in the MVR group and the combined maze procedure groups. The decision for or against an adjunct maze procedure reflected the surgeon's experience. As previously mentioned, however, we omitted the maze procedure for most patients who had multiple previous heart operations, preoperative atrial fibrillation for longer than 20 years, f-wave in $\mathrm{V}_{1}$ leads less than $0.1 \mathrm{mV}$, severely enlarged left atrial dimension greater than $70 \mathrm{~mm}$, or emergency surgery. Thus, the patients who underwent MVR alone may have been at higher risk than those who 
underwent combined procedures. This may be the primary reason for a somewhat lower late survival among the patients with MVR alone than among the patients in the other two groups. Another limitation of this study is that only some of the patients in each group underwent preoperative and postoperative cardiopulmonary exercise tests. Although most patients in each group were in New York Heart Association functional class I or II after the operation, further study to assess the late functional outcomes should be conducted. Although this study confirms the importance of maintaining sinus rhythm in the prevention of late strokes, the precise mechanism behind this process remains unclear. A prospective study would be needed to differentiate the roles of arrhythmia, cardiac function, microbubbles, and other factors in the occurrence of stroke and to determine the most effective regimen of anticoagulation and antiplatelet agents to minimize the risk of late bleeding and stroke.

We conclude that the addition of the Cox maze procedure to MVP and MVR is safe and effective for selected patients. The incidence of late stroke was significantly decreased in patients undergoing combined maze and mitral valve procedures.

We thank Drs Toshihiko Sato, Kanshi Komatsu, and Hiroyuki Konishi for their assistance with statistical analysis and Drs Kazuo Niwaya and Osamu Tagusari for allowing us to include their patients. We also thank Drs. Thomas Sharp and Noel Mills for their constructive comments.

\section{References}

1. Cohn LH, Couper OS, Aranki SF, Rizzo RJ, Kinchia NM, Collins JJ Jr. Long-term results of mitral valve reconstruction for regurgitation of the myxomatous mitral valve. J Thorac Cardiovasc Surg. 1994;107: 143-50.

2. David TE, Armstrong S, Sun Z, Daniel L. Late results of mitral valve repair for mitral regurgitation due to degenerative disease. Ann Thorac Surg. 1993;56:7-12.

3. Brodell GK, Cosgrove D, Schavone W, Underwood DA, Loop FD. Cardiac rhythm and conduction disturbances in-patients undergoing mitral valve surgery. Cleve Clin J Med. 1991;58:397-9.

4. Chua YL, Schaff HV, Orszulak TA, Morris JJ. Outcome of mitral valve repair in patients with preoperative atrial fibrillation: should the maze procedure be combined with mitral valvuloplasty? J Thorac Cardiovasc Surg. 1994;107:208-15.

5. Handa N, Schaff HV, Morris JJ, Anderson BJ, Kopecky SL, EnriquezSarano M. Outcome of valve repair and the Cox maze procedure for mitral regurgitation and associated atrial fibrillation. J Thorac Cardiovasc Surg. 1999;118:628-35.

6. Kosakai Y, Kawaguchi AT, Isobe F, Sasako Y, Nakano K, Eishi K, et al. Cox maze procedure for chronic atrial fibrillation associated with mitral valve disease. J Thorac Cardiovasc Surg. 1994;108:1049-55.

7. Cox JL, Ad N, Palazzo T. Impact of the maze procedure on the stroke rate in patient with atrial fibrillation. $J$ Thorac Cardiovasc Surg. 1999;118:833-40.

8. Cox JL, Jaquiss RD, Schuessler RB, Boineau JP. Modification of the maze procedure for atrial flutter and atrial fibrillation. II. Surgical technique of the maze III procedure. J Thorac Cardiovasc Surg. 1995; 110:485-95.

9. Kosakai Y. How I perform the maze procedure. Operative Techniques Thorac Cardiovasc Surg. 2000;5:23-45.

10. Kobayashi J, Kosakai Y, Nakano K, Sasako Y, Eishi K, Yamamoto F. Improved success rate of the maze procedure in mitral valve disease by new criteria for patients' selection. Eur J Cardiothorac Surg. 1998;13:247-52.

11. Cox JL. Evolving applications of the maze procedure for atrial fibrillation [editorial]. Ann Thorac Surg. 1993;55:578-80.

12. Pasic M, Musci M, Siniawski H, Grauhan O, Edelmann B, Tedoriya $\mathrm{T}$, et al. The Cox maze III procedure: parallel normalization of sinus node dysfunction, improvement of atrial function, and recovery of the cardiac autonomic nervous system. J Thorac Cardiovasc Surg. 1999; 118:287-96.

13. Wolf PA, Mitchel JB, Baker CS, Kannel WB, D’Agostino RB. Impact of atrial fibrillation on mortality stroke, and medical cost. Arch Intern Med. 1998;158:229-34.

14. The Boston Area Anticoagulation Trial for Atrial Fibrillation Investigators. The effect of low dose warfarin on the risk of strokes in patients with non-rheumatic atrial fibrillation. N Engl J Med. 1990; 323:1505-11.

15. Stroke Prevention in Atrial Fibrillation Investigators. Stroke prevention in atrial fibrillation study: final results. Circulation. 1991;84:52739.

16. Verheugt FW. Anticoagulation after artificial valve replacement with or without atrial fibrillation: how much is really needed? Thromb Haemost. 1999;82 Suppl 1:130-5.

\section{Discussion}

Dr Renee Hartz (New Orleans, La). Although Bando and coworkers have clearly demonstrated a marked reduction in morbidity after mitral valve surgery when a maze procedure or a variant of the maze procedure was added to the operation, the validity of referring to a "control" group in this series can be questioned. Perhaps statistical comparisons have been meaningful or more valid if the groups had been referred to as "treatment" and "nontreatment" groups.

Specifically, Dr Bando, please address the following issues. First, in the MVR/maze group, did you consider simply ligating the atrial appendage, with or without adding a reduction in atrial size? With closely monitored anticoagulation, might you not have observed the same freedom from stroke at 5 years as you did with the maze procedure itself?

Second, in the MVP/maze group, the incidence of chronic atrial fibrillation was very high $(95 \%)$, yet $85 \%$ of this cohort had pure mitral regurgitation and therefore presumably degenerative pathophysiology. Yesterday we learned from Carpentier and colleagues that $60 \%$ of the patients in their group with degenerative disease were in normal sinus rhythm after the operation. Can you reconcile this difference? Are you seeing patients later in the course of the disease than are surgeons in some our countries?

By extension, why was your freedom from stroke in this group, the $\mathrm{MVP} / \mathrm{maze}$ group, only $78 \%$ at 5 years? In your article, you refer to "periods of inadequate anticoagulation." Who monitors your patients, and what is your chosen target international normalized ratio?

Finally, did you consider routine appendage ligation in all cases, even in your supposed control group? And did you consider ablation only with mapping techniques in extremely high-risk cases, ablating the site of origin, which we know can be determined before or during the operation?

It has been stated at this meeting and elsewhere that the maze procedure is the criterion standard for the curative treatment of atrial fibrillation. It has been a privilege to discuss this work, especially at a meeting where several presentations have documented expanding indications for this important operation and at which the presidential address was delivered by its inventor. You 
and your group should be commended for reducing the incidence of stroke by any means available in a large group of patients with valvular heart disease who are therefore at high risk for stroke.

Dr Bando. Regarding your first question, part of the answer is that it may not be appropriate to call the MVR alone group a "control" group. As you are aware, this was a nonrandomized retrospective study, and the background characteristics of these three cohorts were different. However, the key message in my presentation is that if you do not do a maze procedure and chronic atrial fibrillation continues, that is the most significant risk factor for late stroke, and in that regard I believe that our observation is valid.

Your second question is whether simple ligation of appendage and the reduction of left atrial size may result in the same effect as the maze operation of preventing late stroke. I think that the answer is no. As indicated in my presentation, 2 patients in the maze group had late strokes after unsuccessful maze procedures, although these patients had left atrial appendage ligation and were receiving adequate anticoagulation at the time of the stroke. Thus, the maintenance of a regular rhythm and re-establishment of atrial contraction is important in preventing stroke.

The third question relates to the MVP in the maze group. As you mentioned, $85 \%$ of this group had mitral regurgitation, but this included predominant mitral regurgitation, and some patients had a component of mitral stenosis as well. Therefore, this does not represent pure mitral regurgitation. In this group $45 \%$ of the patients had rheumatic changes, and this probably resulted in the difference between the Western population and the Japanese population. That may be the reason for the difference between our data and those of Carpentier and colleagues.

Our target international normalized ratio, which is monitored by our cardiologists at the National Cardiovascular Center and by a local physician, is 2.0 to 3.0. This is somewhat lower than the Western standard, but it is based on the preparing guidelines of the Japanese Circulation Society and American College of Chest Physicians.

Finally, would I ligate all atrial appendages? As I mentioned before, I preserve the appendage to maintain the production of atrial natriuretic peptide, but I tie from the outside if I do not have enough time or close from the inside while preserving the appendage.

Dr Lawrence Cohn (Brookline, Mass). I assume these were the classic surgical interruptions of the tracts in the atrium. Do you have experience with the newer radiofrequency techniques? Do you use these at all?

Dr Bando. Actually, we have just started and have done 1 case. 